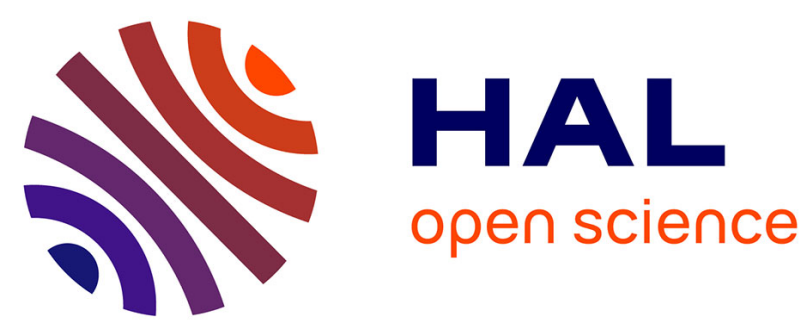

\title{
External iliac artery endofibrosis in an amateur runner: hemodynamic, angiographic, histopathological evaluation and percutaneous revascularization
}

Andrew O. Maree, M. Ashequl Islam, Matija Snuderl, Glenn M. Lamuraglia, James R. Stone, Kari Olmsted, Kenneth A. Rosenfield, Michael R. Jaff

\section{To cite this version:}

Andrew O. Maree, M. Ashequl Islam, Matija Snuderl, Glenn M. Lamuraglia, James R. Stone, et al.. External iliac artery endofibrosis in an amateur runner: hemodynamic, angiographic, histopathological evaluation and percutaneous revascularization. Vascular Medicine, 2007, 12 (3), pp.203-206. 10.1177/1358863X07080844. hal-00571361

\section{HAL Id: hal-00571361 https://hal.science/hal-00571361}

Submitted on 1 Mar 2011

HAL is a multi-disciplinary open access archive for the deposit and dissemination of scientific research documents, whether they are published or not. The documents may come from teaching and research institutions in France or abroad, or from public or private research centers.
L'archive ouverte pluridisciplinaire HAL, est destinée au dépôt et à la diffusion de documents scientifiques de niveau recherche, publiés ou non, émanant des établissements d'enseignement et de recherche français ou étrangers, des laboratoires publics ou privés. 


\title{
External iliac artery endofibrosis in an amateur runner: hemodynamic, angiographic, histopathological evaluation and percutaneous revascularization
}

\author{
Andrew O Maree ${ }^{a}$, M Ashequl Islama, Matija Snuderl ${ }^{b}$, Glenn M Lamuragliac, James R Stone ${ }^{b}$, Kari Olmsted ${ }^{c}$ \\ Kenneth A Rosenfielda and Michael R Jaffa
}

\begin{abstract}
We describe a case of external iliac artery endofibrosis in an amateur competitive runner. The diagnosis was made by a combination of hemodynamic, angiographic and histopathological assessment and percutaneous revascularization was performed using a balloon expandable stent.
\end{abstract}

Key words: amateur runner; Doppler; endofibrosis; iliac artery; intimal hyperplasia

\section{Introduction}

Peripheral arterial disease in healthy young women is unusual and even more so among athletes. Iliac artery endofibrosis is a rare condition predominantly diagnosed in competitive cyclists. ${ }^{1}$ Individuals are typically asymptomatic at rest but develop symptoms with exercise consistent with intermittent claudication. Physical examination is often unremarkable; however, bruits in the iliac fossa have been described. ${ }^{2}$ Varying degrees of unilateral or bilateral external iliac artery obstruction are the most common finding. Management options include medical therapy and endovascular or open vascular surgical repair.

We describe a case of iliac artery endofibrosis in an amateur competitive runner who had dramatic findings on physiologic assessment and who responded well to percutaneous revascularization.

\section{Case report}

A 46-year-old woman was referred for evaluation of exercise-induced left lower limb pain, which had progressed over a 4-year period. She is a competitive amateur runner who initially experienced burning pain

\footnotetext{
aDepartment of Medicine, Vascular Medicine Section, Division of Cardiology, bepartment of Pathology, and ${ }^{\mathrm{c}}$ Division of Vascular and Endovascular Surgery of the General Surgical Services, Massachusetts General Hospital and Harvard Medical School, Boston, MA, USA

Address for correspondence: Michael R Jaff, Harvard Medical School, Vascular Medicine, Massachusetts General Hospital, Boston, MA, USA. Tel: +1 617726 3784; Fax: +1 617724 0371; E-mail: mjaff@partners.org
}

in her left anterior thigh 6-8 miles (10-13 km) into a run. Over the 2 years prior to the current evaluation, symptoms occurred while climbing stairs or walking rapidly up an incline but not while walking on the level. She had sought medical attention from a chiropractor, acupuncturist, sports medicine physician and neurologist. Clinical evaluation, electromyography and muscle biopsy had not yielded a diagnosis.

Upon presentation, she had continued to run despite associated aching thigh pain and intermittent left foot numbness. She had no classic risk factors for vascular disease and had no family history of cardiovascular disease. Physical examination revealed normal lower limb pulses; however, a soft bruit was audible over the left pelvic fossa and femoral artery after exercise. Hematology and biochemical evaluation was unremarkable.

Physiologic assessment revealed normal pulse volume recordings, segmental pressures and anklebrachial indices at rest. Treadmill exercise at $12 \%$ grade and a speed of $6.3 \mathrm{mph}(10 \mathrm{~km} / \mathrm{h})$ induced symptoms after 1 minute. The patient was unable to continue at 3.5 minutes. The right ankle-brachial index following exercise was 1.05. There was no pedal arterial Doppler signal detected following exercise on the left. Duplex ultrasonography revealed a normal abdominal aorta (peak systolic velocity $128 \mathrm{~cm} / \mathrm{s}$ ). The left common and internal iliac arteries were patent (peak systolic velocities $113 \mathrm{~cm} / \mathrm{s}$ and $167 \mathrm{~cm} / \mathrm{s}$, respectively). Diffuse narrowing of the left external iliac artery was detected (peak systolic velocity $250 \mathrm{~cm} / \mathrm{s}$ ) with evidence of post-stenotic turbulence (Figure 1).

Magnetic resonance angiography revealed mild stenosis of the proximal left external iliac artery with less prominent narrowing in a similar distribution on 

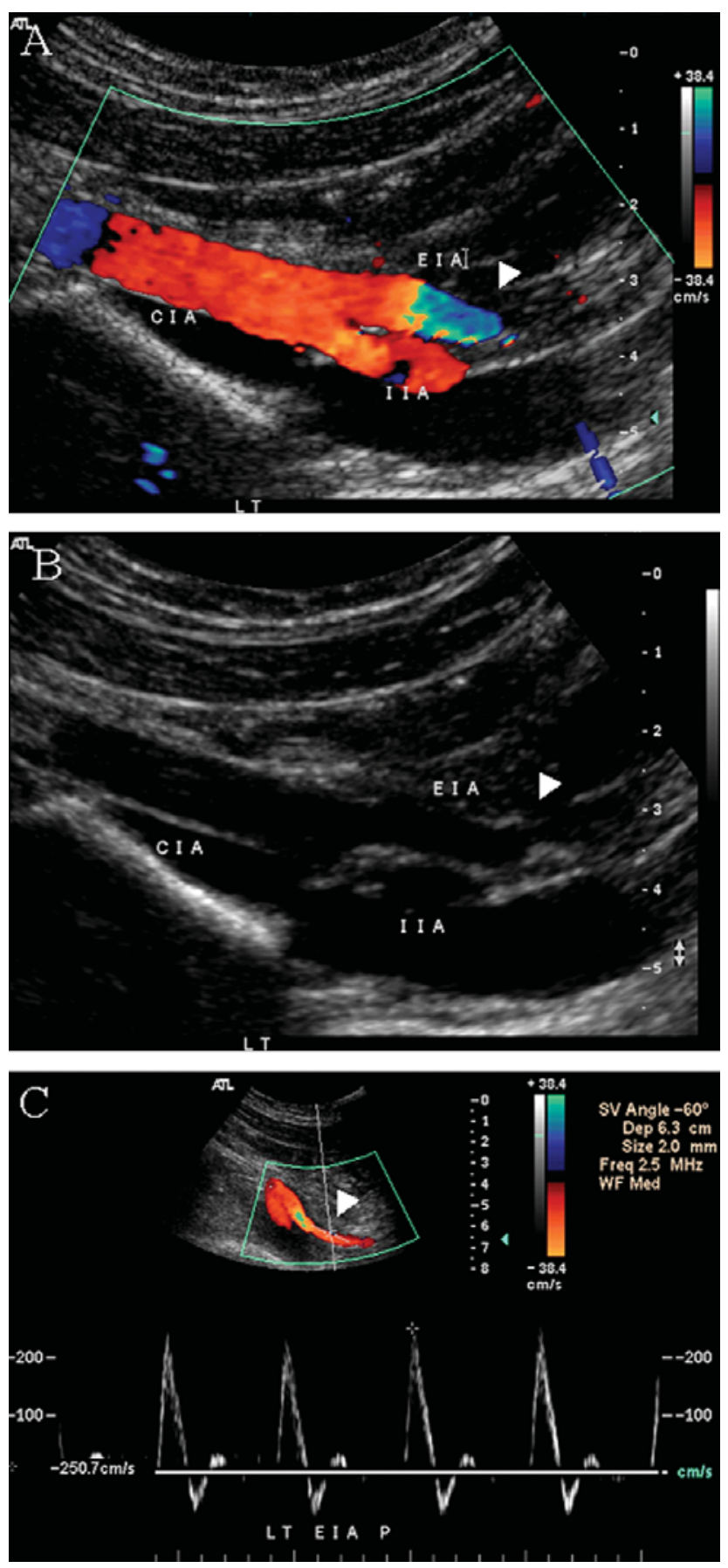

Figure 1 Aorto-iliac duplex scan. The common, external and internal iliac arteries are labeled. Panel A depicts color flow imaging of the iliac bifurcation. The arrowhead indicates a mosaic pattern which represents turbulent blood flow in the proximal external iliac artery. Panel $B$ is an ultrasound image of the same vessel region. The arrowhead indicates an area of focal stenosis in the proximal external iliac artery. Panel C represents the Doppler evaluation of the external iliac artery. The waveform is triphasic with significantly elevated peak systolic flow velocity.

the right side. There was no evidence of extrinsic vascular compression or disease in other vessels.

The differential diagnosis considered at this point included external iliac artery endofibrosis, atherosclerotic vascular disease, healed iliac artery dissection,
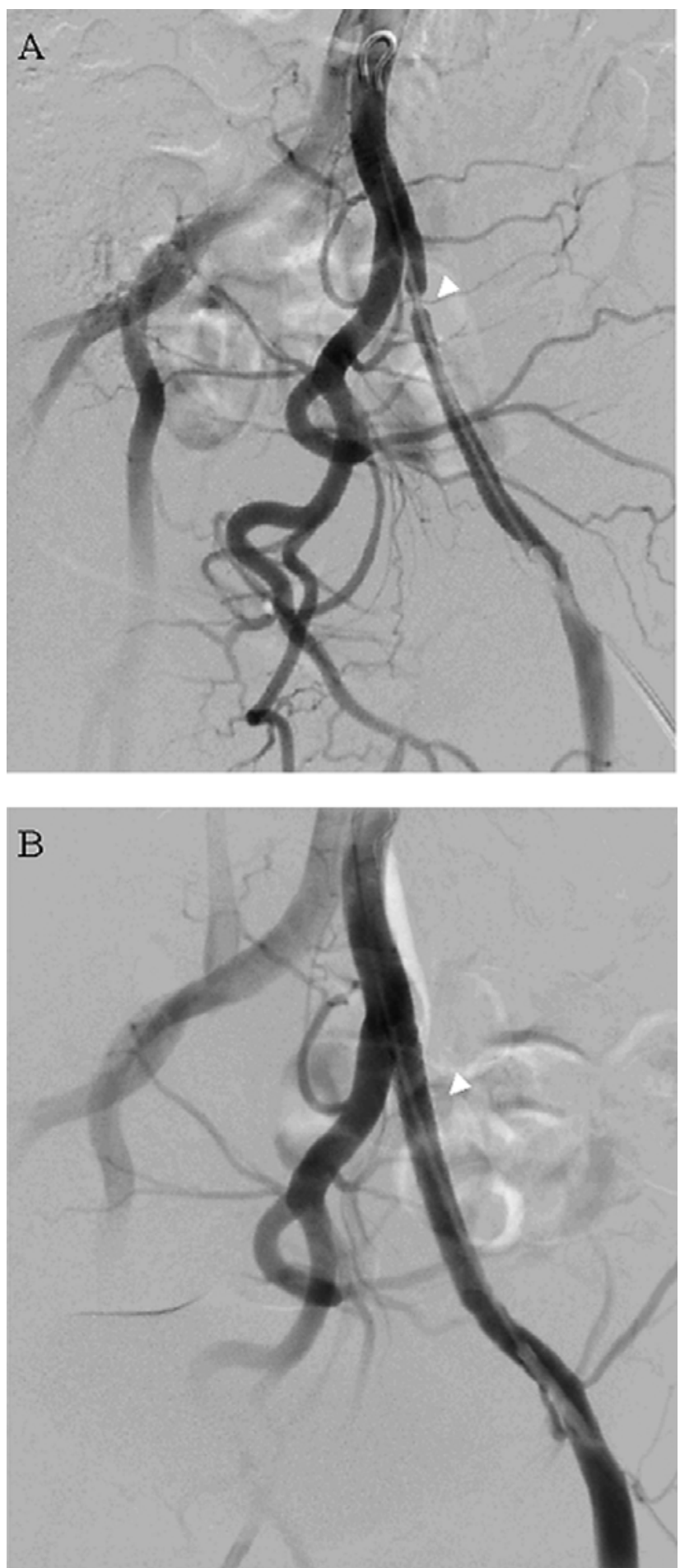

Figure 2 Aorto-iliac digital subtraction angiography in the right anterior oblique projection. Panel A demonstrates the pre-intervention angiogram. An arrowhead indicates a focal stenosis in the left external iliac artery. Panel B shows the post-intervention angiogram and an arrowhead indicates the same region in the left external iliac artery post endovascular stent insertion.

fibromuscular dysplasia, cystic adventitial disease and giant cell arteritis.

The decision was made to proceed to invasive angiographic and hemodynamic assessment and possible 
percutaneous revascularization. Left external iliac arteriography in a steep right anterior oblique caudal projection revealed proximal focal $70 \%$ stenosis beyond the origin of the internal iliac artery and diffuse $40-50 \%$ tapered stenosis distally (Figure 2). Simultaneous assessment of aortic and left common femoral artery pressures revealed a resting translesional gradient of $31 \mathrm{mmHg}$. This augmented to $73 \mathrm{mmHg} 30$ seconds following bolus injection of intra-arterial nitroglycerine. For diagnostic purposes, a tissue sample was obtained within the lesion by endarterectomy with a directional atherectomy device, prior to performing balloon angioplasty and stent deployment $(5.0 \times 59 \mathrm{~mm}$ balloon expandable stent $)$. There was $5 \%$ residual stenosis with no translesional gradient at the conclusion of the procedure. The patient was discharged the following day.

The endarterectomy sample was evaluated by immunohistochemistry. The cells comprising intimal hyperplasia were predominantly smooth muscle cells (reactive for smooth muscle actin) with focal macrophages (reactive for CD68). The sample surface was covered by CD31 positive endothelial cells. There was no evidence of vasculitis or atherosclerosis. Although the histological features were not entirely specific, they are consistent with reactive intimal hyperplasia due to repetitive mechanical injury (Figure 3).

The patient was reassessed 3 months post-procedure and reported no recurrence of symptoms despite full resumption of exercise. Physiologic assessment again confirmed the presence of normal pulse volume recordings, segmental pressures and ankle-brachial indices bilaterally at rest. Baseline ankle-brachial indices were 1.10 in both lower limbs and remained unchanged after exercise. Treadmill exercise at a $15 \%$ grade and speed of $3 \mathrm{mph}(4.8 \mathrm{~km} / \mathrm{h})$ for 5 minutes failed to induce symptoms. Duplex ultrasonography of the left external iliac artery revealed a patent wellopposed endoluminal stent with intact stent architecture. Peak systolic velocities proximal to, within, and distal to the stent were normal.

\section{Discussion}

Intimal hyperplasia can occur as a result of vasculitis, trauma, radiation therapy, collagen vascular disease and metabolic disorders such as hyperhomocysteinemia. It also occurs when inflammatory and/or malignant processes occur in tissue adjacent to the vessel. It may also manifest as a post-bifurcation flow-mediated pre-atherosclerotic process, particularly in smokers. Although the intimal hyperplasia of endofibrosis is not distinguishable histologically from that of the intimal fibroplasia variant of fibromuscular dysplasia, the latter is more frequently focal in distribution and typically involves renal and carotid arteries and less frequently the iliac arteries. ${ }^{3}$ In the absence of evidence of atherosclerosis, vasculitis or systemic vasculopathy, and based on the bilateral disease distribution and clinical history of endurance running, a diagnosis of iliac artery endofibrosis was made.

Endofibrosis of the iliac artery was first described in 1984 and has been predominantly diagnosed in competitive cyclists in the absence of other risk factors for peripheral arterial disease. ${ }^{1}$ Occurrence among runners has been reported, although considerably less frequently. 4,5 Individuals are usually between 30 and 50 years old, typically present with symptoms of intermittent claudication and may have a normal physical examination. Clinical evaluation reveals stenosis of the iliac arterial system, which is frequently unimpressive on angiography. ${ }^{2}$ Stenosis of the external iliac artery is most common; however, the common and internal iliac arteries may also be involved.

Repeated stretching and compression of the external iliac artery at the hip joint, extrinsic compression by a hypertrophic psoas muscle, and enhanced shear forces in the presence of supraphysiological blood flow are some of the proposed pathophysiological mechanisms. ${ }^{6}$ Histopathological findings include luminal thrombosis, intimal hyperplasia/endofibrosis with myofibrobast or smooth muscle proliferation, medial hypertrophy, and adventitial hyperplasia., ${ }^{2,7,8}$
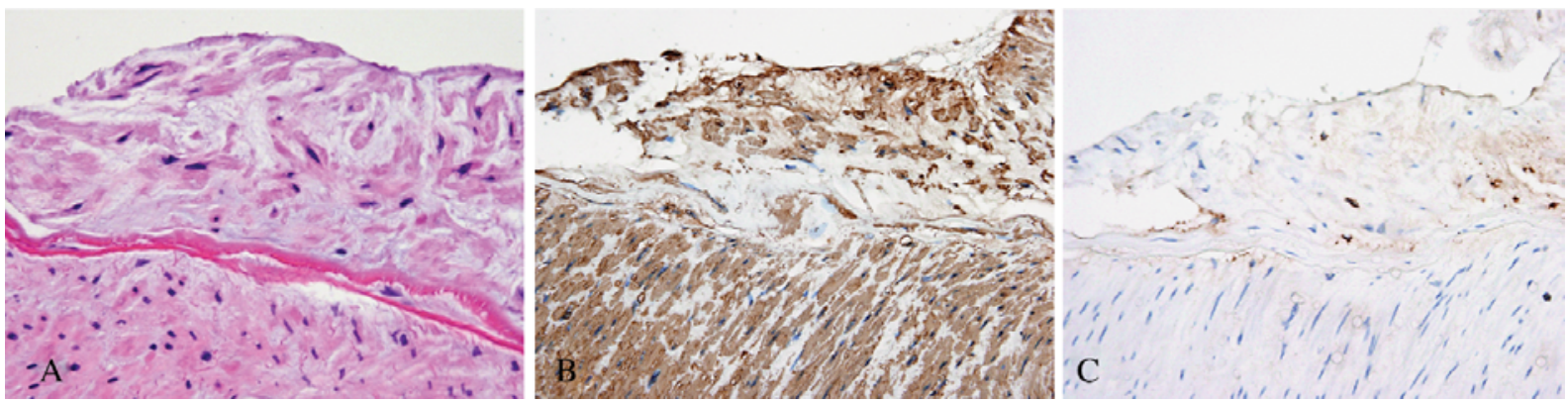

Figure 3 Histopathological evaluation of the left external iliac artery endarterectomy sample. Hematoxylin and eosin staining shows intimal hyperplasia and no evidence of vasculitis or atherosclerosis (Panel A). By immunohistochemistry the cells comprising the intimal hyperplasia are predominantly smooth muscle cells reactive for smooth muscle actin (Panel B) with focal macrophages reactive for CD68 (Panel C). 
Duplex ultrasonography in combination with physiologic testing may be more sensitive than digital subtraction angiography. Pulse volume recording, segmental pressures and ankle-brachial indices with exercise provocation may detect arterial disease when stenosis is less apparent on imaging and therefore these diagnostic modalities should be used in combination.

Most cases reported to date have been managed surgically with either patch angioplasty or an interposition graft. Balloon angioplasty in the absence of stenting has been used; however, symptom recurrence is described. ${ }^{5,6}$ This is the first reported case where balloon expandable stent insertion was used as primary therapy for external iliac artery endofibrosis.

In our preliminary experience, combined clinical examination, imaging and physiological testing were key to the detection of iliac artery endofibrosis. Furthermore, percutaneous angioplasty and stent deployment was associated with procedural success and symptom resolution at short-term follow-up. Further studies are required to discern whether endovascular intervention represents a durable therapy for this condition and may thus reserve more invasive surgical options for endovascular failures.

\section{Conclusion}

Iliac artery endofibrosis is an unusual cause of intermittent claudication; it should be suspected among athletes without classic risk factors for peripheral arterial disease. Despite a normal physical examination, physiologic evaluation in a vascular laboratory, including graded treadmill exercise testing and duplex ultrasonography, should be performed. Arteriography with intra-arterial provocation to elicit translesional pressure gradients is critical to the early diagnosis. Attempts to alleviate the gradient with endovascular methods may represent the primary intervention, reserving surgical intervention for endovascular failures.

\section{References}

1 Walder J, Mosimann F, Van Melle G, Mosimann R. [Iliac endofibrosis in 2 cycling racers.] Helv Chir Acta 1985; 51: 793-95.

2 Kral CA, Han DC, Edwards WD, Spittell PC, Tazelaar HD, Cherry KJ Jr. Obstructive external iliac arteriopathy in avid bicyclists: New and variable histopathologic features in four women. J Vasc Surg 2002; 36: 565-70.

3 Slovut DP, Olin JW. Fibromuscular dysplasia. N Engl J Med 2004; 350: 1862-71.

4 Schep G, Bender MH, Kaandorp D, Hammacher E, de Vries WR. Flow limitations in the iliac arteries in endurance athletes. Current knowledge and directions for the future. Int J Sports Med 1999; 20: 421-28.

5 Ford SJ, Rehman A, Bradbury AW. External iliac endofibrosis in endurance athletes: a novel case in an endurance runner and a review of the literature. Eur J Vasc Endovasc Surg 2003; 26: 629-34.

6 Alimi YS, Accrocca F, Barthelemy P, Hartung O, Dubuc M, Boufi M. Comparison between duplex scanning and angiographic findings in the evaluation of functional iliac obstruction in top endurance athletes. Eur J Vasc Endovasc Surg 2004; 28: 513-19.

7 Chevalier JM, Enon B, Walder J et al. Endofibrosis of the external iliac artery in bicycle racers: an unrecognized pathological state. Ann Vasc Surg 1986; 1: 297-303.

8 Rousselet MC, Saint-Andre JP, L'Hoste P, Enon B, Megret A, Chevalier JM. Stenotic intimal thickening of the external iliac artery in competition cyclists. Hum Pathol 1990; 21: 524-29. 